\title{
Determinação da erosividade da chuva - correlação com eventos de inundações, alagamentos e deslizamentos na cidade de Santa Maria
}

Elisângela Rosemeri CuRti Martins

Mauro Kumpfer Werlang

\section{Resumo}

A cidade de Santa Maria possui várias vilas onde ocorrem conflitos de uso da terra. Esses conflitos evidenciam problemas relacionados a ocorrência de inundações, alagamentos e deslizamentos. Nessa perspectiva, teve-se como objetivos determinar a erosividade da chuva para Santa Maria e estabelecer um índice crítico através da equação de regressão. Determinou-se a erosividade da chuva conforme a proposta de Wischmeier \& Smith (1956), expressa através de El30. Para tanto, trabalhou-se com a série compreendida pelo período de 1980-2002. Em seguida estabeleceu-se a correlação entre a erosividade da chuva e os eventos de inundação, alagamentos e deslizamentos. Obteve-se como índice crítico para o El30 48.55 Mj.ha/ $\mathrm{mm} . \mathrm{h}$ e, um índice crítico para a precipitação acumulada de 31,21 $\mathrm{mm}$ para o desencadeamento dos eventos. 


\section{Abstract}

In Santa Maria, there are so many villages where conflicts dealing with earth occur. Such conflicts highlight problems associated with flooding, leaking and landslide. Considering this information, the objective here is to determine the erosion caused by the rain in Santa Maria, by establishing a critical rate through the regression's equation. The erosion provoked by the rain was determined according to Wischmeier \& Smith's purpose (1956), expressed by El30, from 1980 to 2002. The relationship between erosion, flooging and landslide was established. The critical rate obtained from the El30 was $48.55 \mathrm{Mj}$.hál $\mathrm{mm}$.h and from the rain accumulated to the promotion of the events was $31,21 \mathrm{~mm}$.

\section{Introdução}

Os problemas relativos às formas de uso ocupação da terra, cada vez mais vêm provocando alterações nos processos naturais. Além da expansão das áreas agrícolas, outros fatores tem sido determinantes nas alterações no ambiente, entre eles a expansão urbana e industrial.

A urbanização, historicamente, é resultante da divisão social do trabalho a partir do momento em que o excedente agrícola acumulado "...permitiu que uma porção da população pudesse se desvincular da obtenção direta dos meios de que obtinham para sua subsistência, passando dessa forma poder dedicar-se a outras atividades relacionadas à política, troca de produtos, comércio", (Costa apud Zillmer, 1991, p. 28).

Juntamente com o processo de urbanização vêm os problemas relacionados à segregação espacial e econômica nas cidades, ou seja, o bairro e periferia. O aumento da população reflete um processo que desencadeou a grande expansão dos núcleos urbanos. Assim sendo, as interferências e as perturbações provocadas estão mais visíveis próximos de rios, arroios e córregos, onde, geralmente em função do aspecto legal e baixa valorização imobiliária, instalam-se aquelas pessoas marginalizadas pela segregação social. Vê-se aumentar ainda mais os problemas quando ocorre a retirada da vegetação, presença de lixo e esgoto, com conseqüentes deslizamentos, erosão, assoreamentos, proporcionando maiores riscos de inundações e alagamentos.

A cidade de Santa Maria possui várias vilas onde ocorrem 
conflitos de uso. Nessas, aparecem riscos de acidentes geológicos/ geomorfológios como escorregamentos de solo e rocha. Em relação às drenagens, ocorrem os riscos de acidentes e/ou eventos de inundações e alagamentos.

Os objetivos do trabalho propõem a determinação da erosividade da chuva com base na determinação do índice El30 para a cidade de Santa Maria. Busca levantar as ocorrências oficiais de eventos de inundações, alagamentos e deslizamentos em Santa Maria, no período de 1980 a 2002, determinando um índice crítico para a erosividade da chuva nas ocorrências de inundações, alagamentos e deslizamentos. Propõem estabelecer a correlação entre a erosividade da chuva e ocorrências desses eventos e através dos índices críticos obtidos, subsidiar ações relativas a minimizar o impacto social desses eventos que freqüentemente ocorrem na cidade de Santa Maria.

\section{Materiais e métodos}

2.1. Localização e caracterização geral da área

A cidade de Santa Maria, situada no centro do estado do Rio Grande do Sul, está inserida na região denominada Depressão Central entre as coordenadas geográficas $53^{\circ} 45^{\prime} 00^{\prime \prime}$ e $53^{\circ} 52^{\prime} 30^{\prime \prime}$, de longitude oeste e $29^{\circ} 40^{\prime} 00^{\prime \prime}$ e $29^{\circ} 45^{\prime} 00^{\prime \prime}$ de latitude sul. Apresenta relevo com topografia suave, com baixas cotas altimétricas, onde se destacam planícies aluviais e terraços fluviais. Entretanto, no setor norte junto ao Rebordo do Planalto Meridional Brasileiro, aparecem cotas altimétricas mais elevadas, consequentemente, áreas caracteristicamente mais íngremes. Nas áreas em que o relevo se apresenta plano ocorrem topos modelados em rochas mais resistentes, que funcionam como camada mantenedora. Além destes, aparecem, em alguns pontos, relevos residuais.

No que se refere a vegetação, originalmente, corresponde aos Campos, Floresta Estacional Decidual e áreas de Tensão Ecológica. Em relação aos cursos de água, os mais importantes são o arroio Cadena, arroio Arenal e o Rio Vacacaí Mirim. Todos pertencem à bacia hidrográfica do Rio Jacuí.

No que diz respeito à geologia, a porção urbana de Santa Maria, abrange uma zona de rochas sedimentares e outra com rochas vulcânicas. A área sedimentar está compreendida pela Formação Caturrita, na região central da cidade e pela Formação Santa 
Maria na periferia. Ao norte ocorrem rochas da Formação Botucatu intercaladas com rochas vulcânicas da Formação Serra Geral junto ao Rebordo do Planalto.

O clima, com base na classificação de Köppen, enquadrase como sendo Mesotérmico Brando Cfa. As precipitações são regulares durante todo o ano, não apresentando estação seca.

\subsection{Métodos}

$\mathrm{Na}$ coleta dos dados utilizou-se dos gráficos de registro diário relativos aos eventos de precipitação, considerando-se as chuvas individuais.

Para o levantamento dos dados referentes às ocorrências de inundações, alagamentos e deslizamentos, utilizou-se das Fichas de Ocorrências de Bombeiros (FOBs) da Brigada Militar, BataIhão do Corpo de Bombeiros. Nessas, buscou-se conhecer o relatório das ocorrências com respectivo endereço, dia e condições de tempo.

Fez-se o levantamento dos dados relativos aos eventos de chuva individual registradas no gráfico do pluviógrafo, compreendidos na série de 22 anos (1980-2002), junto ao Departamento da FitotecniaSetor de Meteorologia na Universidade Federal de Santa Maria. A partir dos dados determinou-se a erosividade da chuva seguindo a metodologia proposta por Wischmeier \& Smith (1956). Tem-se a erosividade expressa através do índice $\mathrm{El} 30$ e esse resulta do produto da energia cinética total da chuva pela intensidade máxima, em $\mathrm{mm} / \mathrm{h}$ numa duração de 30 minutos. O fator "R" (erosividade da chuva), é expresso pela unidade $\mathrm{Mj} / \mathrm{ha} \cdot \mathrm{mm} / \mathrm{h}$.

Posteriormente à fase de coleta, com auxílio da Planilha Excel, procedeu-se a tabulação dos dados. Obtido o resultado do índice $\mathrm{El} 30$ relativo a cada chuva individual, considerando cada segmento uniforme, foi determinado o índice El30 mensal e anual da série estudada. Através das médias da série, determinou-se o Fator $\mathrm{R}$.

Para a coleta dos dados, constantes nas Fichas de Ocorrências de Bombeiros (FOBs), esses foram enquadrados conforme o código da natureza da ocorrência. Foram consideradas ocorrências de inundações, alagamentos e deslizamentos aquelas que, no relatório, constatou-se que as condições de tempo eram instáveis ou que havia mais de uma ocorrência registrada no mesmo dia. Entende-se como evento de inundação um tipo particular de enchente, o 
qual apresenta como característica o extravasamento da água para além do canal principal. Como conceito para enchente, considera-se a elevação do nível normal das águas do rio, não ocorrendo o extravasamento do seu leito. Caracterizando o conceito de alagamentos, esses são decorrentes de uma insuficiência de drenagem das águas da chuva, face a uma topografia suavizada, da insuficiência ou inexistência dos sistemas de águas pluviais, ou ambas. Cabe destacar que estes não estão ligados às drenagens como é o caso das enchentes e inundações. No que se refere a conceituação de deslizamento, Penteado (1978) faz referência aos movimentos de massa (lentos ou rápidos) quais são provocados por atividades biológicas ou condições climáticas e seus aspectos físicos. Entretanto, destaca como principal fator a ação da gravidade. Classifica como movimento de massa rápidos, os fluxos de terra, fluxos de lama, desmoronamentos e deslizamentos, que podem ser intermitentes, repentinos ou contínuos. Destaca como movimentos de massa lentos, a solifluxão e o rastejamento. Os movimentos de massa são, portanto, movimentos do solo e do regolito saturados. Também nesse sentido, conceituando deslizamento e desmoronamento, Christofoletti (1980) refere-se à deslizamento como sendo deslocamento de uma massa de regolito sobre um embasamento saturado de água. A função de nível de deslizamento pode ser dado por uma rocha sã ou por um horizonte de regolito possuidor de maior quantidade de elementos finos, de siltes ou argilas, favorecendo atingir de modo mais rápido o limite de plasticidade e do de fluidez. Desmoronamentos são deslocamentos rápidos de bloco de terra, quando o solapamento criou um vazio na parte inferior da vertente, ocorrendo geralmente em vertentes íngremes.

Buscando a correlação entre os dados de precipitação, erosividade da chuva e os eventos registrados, considerou-se o volume de chuva acumulada relativa a quatro dias antecedentes ao evento. A consideração de um período de quatro dias está apoiada em Tatizana et al (1987), que definiu este número de dias de chuva antecedentes quando analisou ocorrências de escorregamentos na Serra do Mar em Cubatão - SP.

A relação que se buscou estabelecer, fez-se considerando o número de ocorrências e o índice El30. Obteve-se assim uma equação de regressão com base nos dados da série estatística trabalhada. 


\section{Resultados e discussão}

3.1. Correlação entre erosividade da chuva, eventos de inundações, alagamentos e deslizamentos

Através da determinação da erosividade da chuva, para a cidade de Santa Maria, chegou-se às médias mensais do indice El30. O período de pesquisa da série analisada, está representada no Quadro 1.

Os dados do Quadro 1, expressam o El30 (produto da energia cinética total da chuva pela intensidade máxima em $\mathrm{Mj} / \mathrm{ha}$ em uma duração de 30 minutos). Esses valores correspondem a erosividade da chuva, determinada conforme as características locais de precipitação, ou seja, representam a erosividade destas, caracterizando-a para Santa Maria-RS.

Pode-se observar, pelos dados do Quadro 1, que a maior erosividade corresponde ao mês de dezembro, seguido de janeiro, março e fevereiro, respectivamente. Caracteriza-se, dessa forma, o período com maior erosividade da chuva, o verão. Observa-se também que nos meses relativos à passagem do verão para o outono, do outono para inverno e, inverno para primavera, o índice de erosividade manifesta-se menor. Isso deve-se ás condições de tempo locais.

No verão os eventos de precipitações são mais torrenciais, consequentemente mais erosivas, uma vez que representam precipitações num intervalo de tempo menor, comparativamente aos eventos de precipitação no inverno. No inverno as condições de tempo caracterizam-se, muitas vezes quando da ocorrência de precipitação, por frentes que ficam estacionadas no RS, provocando precipitações ao longo de dias. Essas tornam-se menos erosivas face a intensidade de precipitação e a determinação do índice EI30, quando comparadas aos períodos de verão, outono e primavera, respectivamente.

O número de ocorrências relativas a eventos de inundações, alagamentos e deslizamentos levantadas chegou a um total de 156 ocorrências para o período. Com base nos dados referentes ao número de ocorrências e erosividade da chuva, obteve-se o gráfico de dispersão (Figura 1). Cruzou-se o número de ocorrências, segundo cada ano, e a erosividade da chuva média anual, visando estabelecer um índice crítico deste para ocorrências desses tipos de eventos. A Figura 1 mostra o resultado obtido. 
QUADRO 1 : Médias mensais do índice El30 e erosividade da chuva para Santa Maria-RS.

\begin{tabular}{|c|c|c|c|c|c|c|c|c|c|c|c|c|}
\hline Ano & 1980 & 1981 & 1983 & 1984 & 1985 & 1986 & 1987 & 1988 & 1989 & 1990 & 1991 & 1992 \\
\hline Jan & 568.9 & 806.1 & 116.5 & 330 & 726 & 92.6 & 93.6 & 119 & 58.4 & 150 & 67.2 & 212.6 \\
\hline Fev & 130.5 & 69.4 & 135.6 & 409.7 & 205 & 77 & 431.0 & 119 & . & 315.9 & . & 214.2 \\
\hline Mar & 190.2 & 33.1 & 157.8 & 193.9 & 287.2 & 100.5 & 213.3 & 135.9 & 364.5 & 178.2 & 213.4 & 143.1 \\
\hline$A b r$ & 29.0 & 45.9 & 147.9 & 424.5 & 198.6 & 89.3 & 40.7 & 376.1 & 380.9 & 220.7 & 789.6 & 393 \\
\hline Mai & 38.3 & 35.2 & 135.8 & 518.9 & 159.2 & 652.8 & 188.3 & 17.6 & 58.3 & 50.0 & 73.2 & 63.09 \\
\hline Jun & 39.0 & 181.5 & 24.07 & 160.9 & 197.9 & 75.9 & 137.5 & 346.6 & 20.7 & 20.9 & 52.2 & 106.1 \\
\hline Jul & 107.8 & 41.1 & - & 212.5 & 206.5 & 119.3 & 186.2 & . & 40.8 & 259 & 63.8 & 32.76 \\
\hline Ago & 11.5 & & 67.6 & 101.1 & 44.4 & 208.7 & 210.6 & - & 133.6 & 7.6 & 11.9 & 242.5 \\
\hline Set & 100.0 & 82.5 & - & 107.8 & 100.9 & 208.7 & 84.8 & 311 & 149.6 & 112.8 & 151.8 & 75.99 \\
\hline Out & 107.3 & 161.3 & 123.7 & 56.2 & 92.4 & 40.6 & 291.2 & 292.5 & 177.2 & 116.4 & 78.3 & 90.27 \\
\hline Nov & 19.5 & 166.5 & - & 155.5 & 43.5 & 143.4 & 258.0 & 399.6 & 218 & 235.3 & 32.31 & 101.2 \\
\hline Dez & 235.6 & 478 & - & 65.6 & . & 211 & 734.2 & 186 & 183.9 & 112.3 & 350.1 & 209 \\
\hline Média & 131.5 & 191 & 113.6 & 228 & 205.6 & 168.3 & 239.1 & 230.3 & 162.3 & 148.2 & 178.9 & 157 \\
\hline Ano & 1993 & 1994 & 199 & 1996 & 1997 & 1998 & 1999 & 2000 & 2001 & 2002 & Média & Mês \\
\hline Jan & 128.8 & 270.6 & 63.6 & 511.8 & 149.6 & 254 & 352.1 & 415 & 355.6 & 136.2 & 271 & .74 \\
\hline Fev & 248 & 411.8 & 70.0 & 250.5 & 178.6 & 239.1 & 193.3 & 48 & 223.3 & 384.3 & 229 & 9.17 \\
\hline Mar & 190.4 & 79.1 & 328.4 & 319.7 & - & 126.9 & 239.8 & 228.8 & 439.5 & 260.8 & 233 & 3.80 \\
\hline $\mathrm{Abr}$ & 212.1 & 241 & 78.4 & 159.5 & 104.1 & 275.8 & 127.2 & 32.4 & 182.7 & 345.1 & 222 & .48 \\
\hline Mai & 258.7 & 873.9 & 68.6 & - & 373.6 & 53.8 & 252.7 & 124.7 & 129.4 & 300.8 & 221 & .34 \\
\hline Jun & 81.8 & 152.9 & 84.8 & 162.3 & 199.4 & 41.3 & 167.9 & 250.6 & 120 & 302 & 133 & 3.02 \\
\hline Jul & 208.7 & 389.6 & 64.6 & 41.9 & 129.2 & 129 & 51.4 & 89.6 & 278.8 & 72.2 & 143 & 3.42 \\
\hline Ago & - & 212.7 & 116 & 72.3 & 181.5 & 290.4 & 22 & 113.4 & 109.2 & 198 & 130 & .83 \\
\hline Set & 195.2 & 160.5 & - & 45.1 & 34.6 & 295.6 & 117 & 287.1 & 150.6 & 353.5 & 164 & .48 \\
\hline Out & 173.5 & 316.3 & 47.7 & 95.5 & 220.3 & 47.8 & 160.6 & 143.6 & 79.1 & 152.7 & 139 & .30 \\
\hline Nov & 280.1 & 362.6 & - & 28.4 & 157.3 & 72.3 & 90.1 & 131.7 & 125.4 & - & 167 & .81 \\
\hline Dez & 246.6 & 378.9 & 59.5 & 344.1 & 312.2 & 152.4 & 542.2 & 452.9 & 67.7 & - & 295 & .68 \\
\hline Média & 202.2 & 320.8 & 98.16 & 184.6 & 185.5 & 164.8 & 193 & 193.1 & 188.4 & 250.5 & & \\
\hline & & & & & & & & & \multicolumn{2}{|c|}{ Fator "R" } & \multicolumn{2}{|c|}{$2.353,07$} \\
\hline
\end{tabular}

\footnotetext{
1982- Dados não disponíveis

Organização: Dos autores.
} 


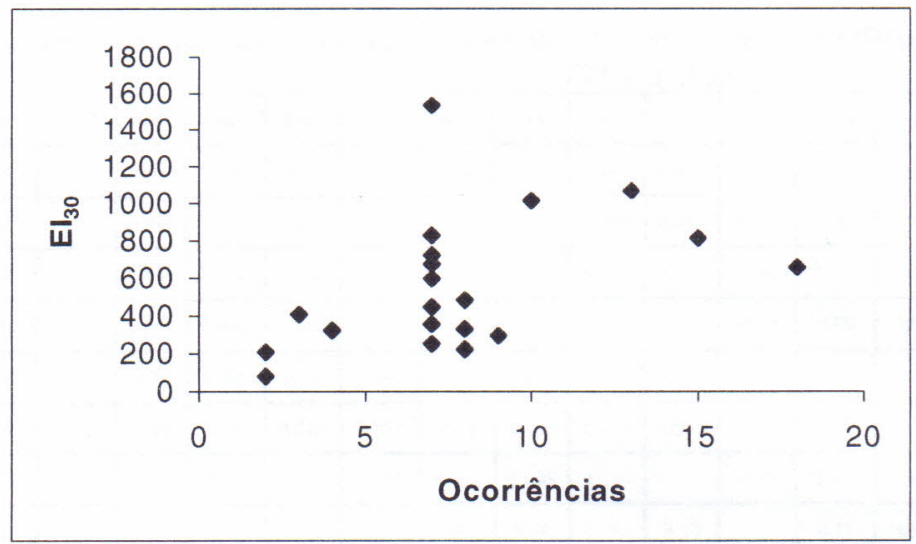

Fig.1: Gráfico da dispersão da média anual do El30 segundo as ocorrências de inundações, alagamentos e deslizamentos Organização: Dos autores.

A dispersão dos dados, considerando as médias anuais para as ocorrências, não é definidora de uma tendência. As médias acabam destoando a realidade em relação as ocorrências na maioria dos casos. Porém, pode-se constatar que, a maior concentração de ocorrências está entre 7 e 9 casos por ano, representado por um El30 que varia entre 251.56 a $829.42 \mathrm{Mj} . \mathrm{ha} / \mathrm{mm}$.h. Isso leva a dizer que quando a erosividade atinge esses limites, há grande probabilidade de ocorrência desses eventos. Entretanto observa-se que na medida que aumenta a erosividade, há um aumento do número de ocorrências, declinando a seguir. Isso se dá em função de que a ocorrência desses eventos é desencadeada com índices menores que $829.42 \mathrm{Mj}$.ha/mm.h. A partir desse valor ocorrem com menor freqüência. Nesse sentido, buscou-se obter a equação de regressão e respectivo coeficiente de determinação $\left(r^{2}\right)$. A Figura 2 mostra que na medida que aumenta a precipitação aumenta a erosividade da chuva, e ambos aumentam o risco de ocorrências dos eventos de inundação, alagamentos e deslizamento. A partir de determinados valores para o $\mathrm{EI} 30$, há uma tendência de aleatoriedade. Entretanto, tem-se caracterizada uma tendência até os valores próximos aos 829.42, conforme a equação 1:

$$
Y=0.0777 x+27.441 \quad r^{2}=0.9511
$$




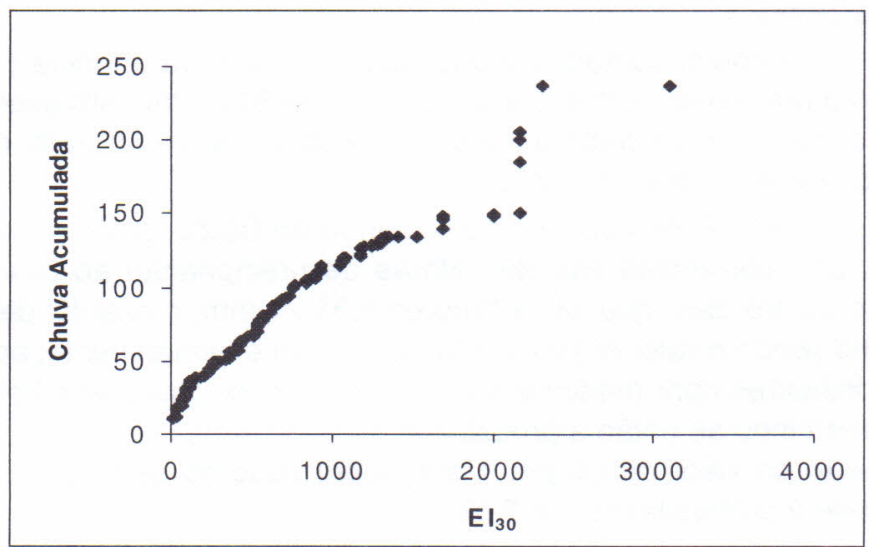

Fig 2: Gráfico de dispersão: Chuva Acumulada e El30 Organização: Dos autores.

Com objetivo de determinar um valor crítico, a partir do qual espera-se o desencadeamento desses eventos, determinou-se a Média e o Desvio Padrão das chuvas e do índice EI30, constantes na tabela 1.

TABELA 1: Média e Desvio Padrão da chuva acumulada e do índice El30.

\begin{tabular}{lclc}
\hline \multicolumn{2}{c}{ Chuva Acumulada } & \multicolumn{2}{c}{ El30 } \\
\hline Média & 77.21 & Média & 640.83 \\
Desvio Padrão(S) & 47.16 & Desvio Padrão (S) & 592.28 \\
Média + 1S & 124.37 & Média + 1 S & 1233.11 \\
Média - 1S & 30.05 & Média - 1 S & 48.55 \\
Média + 2 S & 171.53 & Média + 2 S & 1825.39 \\
Média - 2 S & 17.11 & Média - 2 S & 543.73 \\
\hline
\end{tabular}

Organização: Dos autores. 
Considerando a média menos um desvio padrão determinou-se um valor crítico para o índice EI30. Dessa maneira chuvas acumuladas com EI30 entre 48,55 e 1233,11 são desencadeadoras desses eventos.

Também, conforme a equação definida para o índice EI30, quando a precipitação alcançar um mínimo de $31,21 \mathrm{~mm}$ em eventos de precipitação acumulado durante quatro dias, tendem a partir desse valor, desencadear eventos.

Pelos dados obtidos no Batalhão do Corpo de Bombeiros, destes 21 ocorrências são de valores de precipitação acumulada durante quatro dias, que são inferiores a $31,21 \mathrm{~mm}$, o qual foi definido como sendo o valor crítico. Portanto, podem eventualmente, acontecer desastres com precipitação inferior ao valor crítico estabelecido. Determinou-se então a probabilidade de ocorrência desses eventos abaixo do valor crítico em 1 ano. Com base na série estudada obteve-se a probabilidade de $5 \%$.

Observou-se durante a coleta dos dados de inundações e alagamentos que muitas dessas ocorrências estão relacionadas a problemas de infra-estrutura urbana. Os alagamentos de ruas e casas decorrem de problemas como o entupimento da rede de esgoto. Por outro lado, há relatos que a estrutura não comportou a demanda dada a intensidade da chuva.

Assim, a erosividade da chuva, associada a erodibilidade do solo na área urbana acarreta na destruição de redes de água e esgoto, do sistema viário e também nas edificações.

Também constatou-se que um dos maiores problemas está relacionado ao assoreamentos principalmente do arroio Cadena, associado aos problemas de lixo e esgoto.

\section{Considerações finais}

Considerando os objetivos propostos para o trabalho, os resultados obtidos para a determinação da erosividade da chuva revelaram que os maiores índices El30 ocorrem nos meses de dezembro, janeiro, março e fevereiro respectivamente. Isso evidencia que as precipitações nesses meses, dada as condições de tempo locais, apresentam-se mais erosivas.

$\mathrm{Na}$ correlação entre o número de ocorrências anuais e erosividade da chuva, constatou-se que utilizando-se desta, considerando a média, não foi possivel determinar uma tendência. Os melhores resultados foram obtidos empregando-se os valores da chuva 
acumulada e a erosividade correspondente para cada ocorrência. Partindo-se desse princípio, ao considerar todas as ocorrências e o EI30 correspondente, pôde-se estabelecer um índice crítico, através da média da chuva acumulada e El30 de todas as ocorrências. Chegou-se ao índice $48.55 \mathrm{Mj}$.ha/mm.h como sendo o valor crítico para a série estudada.

Através da definição da equação, precipitações acima 31,21 $\mathrm{mm}$ no período acumulado de quatro dias são susceptíveis de desencadear eventos de inundações, alagamentos e deslizamentos. Entretanto em um total de 156 ocorrências, observou-se que destas, 21 ocorrências são de valores de precipitação inferiores ao valor crítico. Assim tem-se a probabilidade de ocorrências, dentro de 1 ano, de pelo menos $5 \%$ desses eventos com precipitação inferior a esse valor.

Pode-se constatar nas Fichas de Operação de Bombeiros, quando na coleta dos dados das ocorrências, que há grande problema relacionado à infra estrutura urbana. Essa muitas vezes não suporta a capacidade da vazão da água, e, aliado ao entulhamento das tubulação facilita a ocorrência de alagamentos. Isso proporciona aumento dos problemas com conseqüências sociais e econômicas. Esse tipo de relato foi mais constante com relação às áreas de encostas, em áreas ocupadas de várzeas, baixadas e em margens de arroios.

Sugere-se um estudo com um maior detalhamento buscando relacionar as áreas mais susceptíveis, consideradas as condições de infra estrutura e do ambiente, com base na série estudada para Santa Maria-RS.

\section{Referências bibliográficas}

AYOADE, J. O. Introdução à Climatologia para os Trópicos. São Paulo: Difel, 1986, 332p.

BERGER, M. G. Inundações/Alagamentos na Área Urbana de Santa Maria Associado à Ação Antrópica e a Distribuição das Chuvas entre 1980 e 1995. 1999, 82f. Trabalho de Graduação (Curso de Geografia) Universidade Federal de Santa Maria, Santa Maria, 1999.

CERRI, L. E. S. Riscos Geológicos Urbanos. In: Chassot, A. \& Campos, H. (orgs). Ciências da Terra e o Meio Ambiente. São Leopoldo: Ed. Unisinos, 1999. p.133-150. 
CHRISTOFOLETTI, A. Geomorfologia. São Paulo: Edgard Blucher, 1980. 188p.

FERNANDES, N. F. \& AMARAL, C. P. Movimentos de Massa: uma abordagem geológica-geomorfológica. In: CUNHA, S. B. \& GUERRA, A. J. T. Geomorfologia e Meio Ambiente. Rio de Janeiro: Bertrand Brasil; 1996. p.123-194.

MACIEL FILHO, C. L. Carta Geotécnica de Santa Maria. Santa Maria, Imprensa Universitária, 1990. 22p.

MITCHELL, J. K. Estimación de la Perdida del Suelo. In: Kirkby, M. J. \& Morgan, R. P. C. (orgs). Erosión de Suelos. México: Limusa Noriega Editores, 1994. p. 35-88.

MOJICA, F. J. La Ecuacion Universal de Erosion. Revista Geografia de América Central. Escuela de Geografia (Faculdade de Ciencias de la Turma Yelmar) Universidad Nacional Heredia. Costa Rica. Pesquisa em Geografia, p. 35-45, 1978.

PENTEADO. M. Fundamentos de Geomorfologia. 2 ed. Rio de Janeiro: IBGE, 1978. 154p.

TATIZANA, C., OGURA, A. T., CERRI, L. E. S. \& ROCHA, M. C. M. Análise de Correlação entre chuvas e escorregamentos na Serra do Mar, município de Cubatão. In: Congresso Brasileiro de Geologia de Engenharia, São Paulo: ABGE. 1987. v. 2. p.225-236. Anais.

ZILLMER, R. J. A pequena produção da horti-fruticultura na periferia urbana de Santa Maria-RS. 1991. 155f. Trabalho de Graduação (Graduação em Geografia), Universidade Federal de Santa Maria, Santa Maria, 1991.

Elisângela Rosemeri Curti Martins

Mauro KumpferWerLANG Departamento de Geociências - CCNE Universidade Federal de Santa Maria Santa Maria, RS - Brasil 